\title{
Undernutrition and malaria in pregnancy - a dangerous dyad?
}

Holger W. Unger ${ }^{1,2}$, Per Ashorn $3,4,5$, Jordan E. Cates ${ }^{6}$, Kathryn G. Dewey ${ }^{7}$ and Stephen J. Rogerson ${ }^{*}$

\begin{abstract}
Background: In low-resource settings, malaria and macronutrient undernutrition are major health problems in pregnancy, contributing significantly to adverse pregnancy outcomes such as preterm birth and fetal growth restriction. Affected pregnancies may result in stillbirth and neonatal death, and surviving children are at risk of poor growth and infection in infancy, and of non-communicable diseases in adulthood. Populations exposed to macronutrient undernutrition frequently reside in malaria-endemic areas, and seasonal peaks of low food supply and malaria transmission tend to coincide. Despite these geographic and temporal overlaps, integrated approaches to these twin challenges are infrequent.

Discussion: This opinion article examines the current evidence for malaria-macronutrition interactions and discusses possible mechanisms whereby macronutrient undernutrition and malaria may interact to worsen pregnancy outcomes. Macronutrient undernutrition dysregulates the immune response. In pregnant women, undernutrition may worsen the already increased susceptibility to malarial infection and could impair development of protective immunity to malaria, and is likely to exacerbate the impact of placental malaria on fetal growth. Malarial infection, in turn, can drive nutritional depletion; poor gestational weight gain and weight loss in pregnancy increases the risk of adverse pregnancy outcomes. Despite a commendable number of studies and trials that, in isolation, attempt to address the challenges of malaria and undernutrition in pregnancy, few dare to venture beyond the 'single disease - single solution' paradigm. We believe that this may be a lost opportunity: researching malaria-nutrition interactions, and designing and implementing integrated interventions to prevent and treat these commonly co-existing and intertwining conditions, may markedly reduce the high burden of preterm birth and fetal growth restriction in affected areas.
\end{abstract}

Conclusion: We call for more collaboration between researchers studying malaria and nutrition in pregnancy, and propose a research agenda to address this important twin health problem.

Keywords: Pregnancy, Malaria, Nutrition, Low birthweight, Fetal growth restriction

\section{Background}

Pregnancy and early childhood (the first 1000 days of life) are critical periods that determine short- and long-term health outcomes [1]. In low- and middle-income countries (LMICs), two important barriers to a successful pregnancy outcome are maternal undernutrition, which contributes to 800,000 neonatal deaths annually [2], and malaria, estimated to cause approximately 900,000 low birthweight (LBW) deliveries and over 100,000 infant deaths annually $[3,4]$. Infant undernutrition, including fetal growth

\footnotetext{
*Correspondence: sroger@unimelb.edu.au

'Department of Medicine at the Doherty Institute, The University of

Melbourne, Melbourne, Victoria, Australia

Full list of author information is available at the end of the article
}

restriction (FGR), contributes to $45 \%$ of deaths in children under 5 years, and may lead to chronic disease in adulthood [2,5]. Ending the malaria epidemic and addressing the nutritional needs of children, adolescent girls and pregnant women form key components of the recently-launched Global Strategy for Women's Children's and Adolescent's Health for 2016-2030 [6].

The World Health Organization's (WHO) Sustainable Development Goals include ending hunger and malnutrition; reducing maternal, newborn and child mortality; and ending infections such as malaria [7]. In LMICs, populations are often affected by both hunger and malaria [2, 8], and the two may interact (Fig. 1). Nutritional status and intake of specific nutrients may affect 


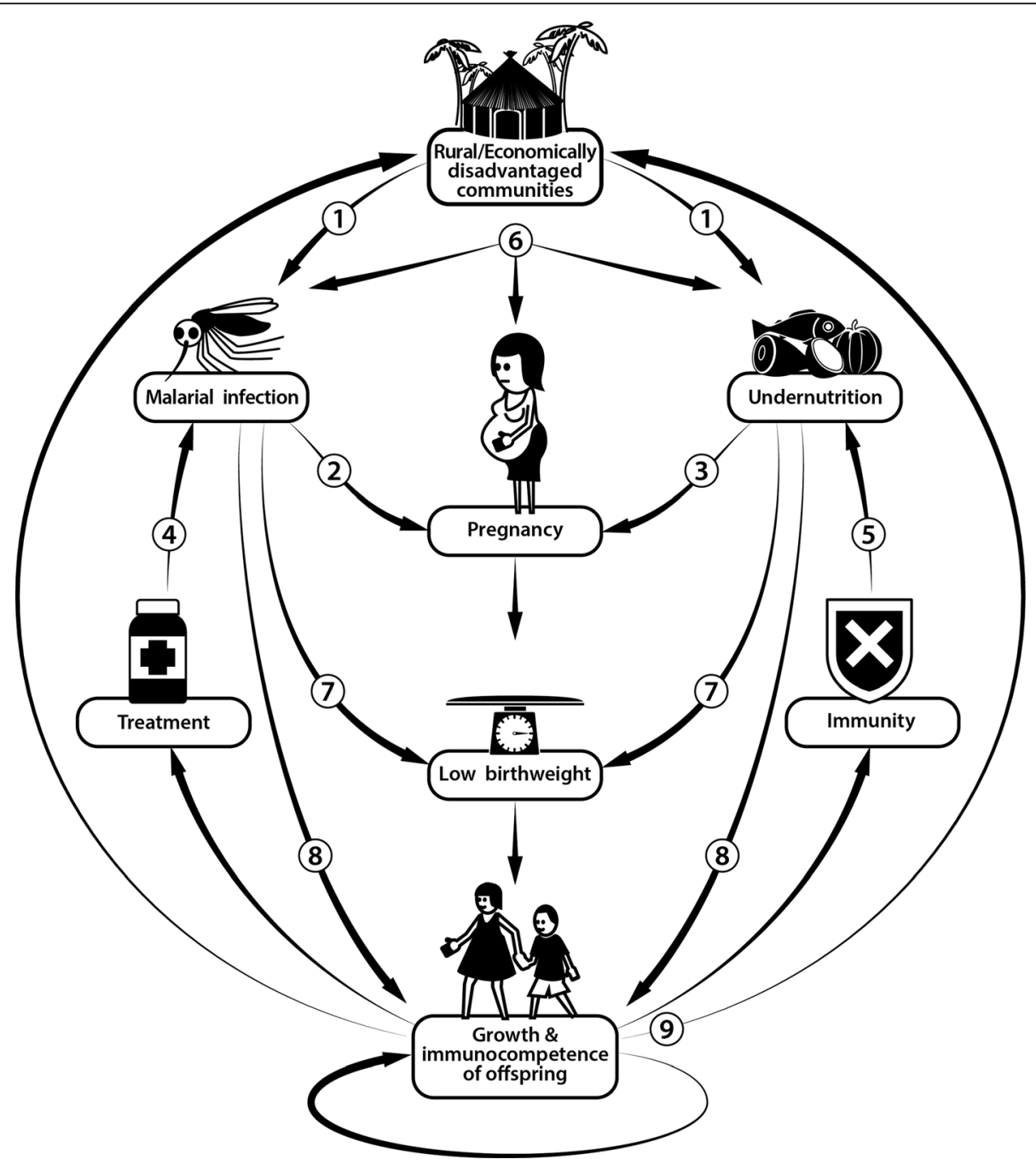

Fig. 1 Interactions between macronutrient undernutrition and malaria. 1) Undernutrition is common in areas where malaria prevalence is high, and rural and economically disadvantaged communities are often most affected. 2) Pregnant women are more likely to be bitten by malariainfected mosquitoes, and are more susceptible to malaria infection. 3) Undernutrition is common in pregnant women, and short inter-pregnancy intervals may lead to nutritional depletion. 4) Undernutrition may impair antimalarial treatment efficacy. 5) Nutritional status and nutrient supplementation may affect antimalarial immunity. 6) Malaria and undernutrition may interact to worsen pregnancy outcomes. 7) Both malaria and undernutrition are important causes of low birthweight. 8) Malaria and undernutrition may affect growth and immunocompetence in the offspring. 9) These combined effects of malaria and undernutrition may have long-term health and socioeconomic consequences extending into adult life and passed on transgenerationally

immunity, modulating an individual's ability to control and clear infection [9]. In turn, infection and associated inflammatory processes increase energy expenditure and protein catabolism, draining nutritional reserves. Of the many potential nutrition-infection interactions in pregnancy [10], malaria is especially important, being the leading preventable cause of LBW in Africa.

A growing body of evidence suggests that malaria and maternal undernutrition interact to worsen pregnancy outcomes. However, interventions to protect pregnant women and their fetuses from macronutrient undernutrition and gestational malaria remain poorly integrated. Our belief is that maternal nutrient deficiency remains a neglected public health problem, and that few successful interventions in this area have adequately dealt with malaria as a cofactor. In this call for increased collaboration between malaria and nutrition experts, we discuss the evidence for malaria-nutrition interactions in pregnancy, with a focus on macronutrient undernutrition, as this remains relatively understudied, notwithstanding the importance of micronutrient deficiencies. Macronutrient undernutrition refers to insufficient consumption of carbohydrates, fats and proteins, and is typically assessed using anthropometric measures in resource-limited settings. We summarise currently available tools to prevent and treat macronutrient undernutrition and malaria in 
pregnancy and outline key research questions that may advance our understanding of gestational malarianutrition interactions with a view to developing novel approaches to improve pregnancy outcomes in LMICs.

\section{Burden of malaria and macronutrient undernutrition in pregnancy}

Each year, 125 million pregnant women, mostly in subSaharan Africa and Asia, are at risk of malaria infection [8]. Worldwide, at least $10 \%$ of pregnant women are undernourished, defined as a pre-pregnancy body mass index (BMI) of less than $18.5 \mathrm{~kg} / \mathrm{m}^{2}$, with prevalence being highest, again, in LMICs in Africa and Asia [2]. Severe maternal undernutrition is rare outside of famine and conflict situations, but moderate undernutrition is common, and associated with LBW $[2,11,12]$.

\section{Current evidence for malaria-macronutrition links in pregnancy}

There is evidence for geographical, socio-economic, temporal and mechanistic links between malaria and macronutrient undernutrition (Fig. 1). Global distribution maps of malaria transmission and undernutrition statistics clearly highlight a broad geographical overlap. Undernourished individuals, including pregnant women, are more likely to live in economic and environmental circumstances that favour malaria exposure [2]. Arguably, these overlaps in disease geography and exposure risk alone provide sufficient proof of need to design interventions that prevent and treat both malaria and undernutrition in pregnancy and infancy.

Malaria and macronutrient undernutrition in pregnancy are also linked temporally. In pregnant Gambian women, the incidence of FGR, preterm birth (PTB) and malaria were all highest late in the hunger season [13], the part of the rainy season before harvest begins. In the same setting, food supplements (high-energy groundnut biscuits) had most impact on birthweight over this period [14]. These results suggest that simple environmental co-incidence of both conditions worsens pregnancy outcomes (whether in an additive or synergistic manner remains unknown), and/or that acute macronutrient shortages increase the risk and impact of gestational malaria (effect measure modification). These findings urgently require confirmation.

Macronutrient undernutrition is associated with increased malaria morbidity and mortality in children and non-pregnant adults, suggesting important immunological interactions $[15,16]$. Malaria, in turn, causes nutritional depletion and worsens child undernutrition [17]. Such interactions are likely to exist in pregnancy [18]. Whether undernutrition alters pregnant women's risk of contracting malaria infection is unknown, but in the Democratic Republic of Congo women with low mid-upper arm circumference (MUAC) and low BMI were most likely to have high placental parasite loads [19].

Studies suggest that the effect of Plasmodium falciparum infection on fetal growth and birthweight is more pronounced amongst women with macronutrient undernutrition compared to well-nourished women $[18,20,21]$. In the Democratic Republic of Congo, the effects of maternal $P$. falciparum parasitaemia on uteroplacental flow and fetal growth were most pronounced amongst undernourished women (low MUAC or BMI) $[18,20]$. Similarly, in Kenya, an association between peripheral $P$. falciparum infection and reduced birthweight was only reported amongst women with a low BMI [21].

\section{Fetal and postnatal effects}

While poor nutrition and malaria have important adverse consequences for maternal health, the developing fetus is most affected. This can have severe immediate as well as long-term consequences - the foundations for an effective immune system, adequate growth, and short- and long-term health are laid in utero [5]. Macronutrient undernutrition and malarial infection have been independently associated with FGR, PTB and stillbirth $[1,11,22]$, and the risk of adverse outcomes may be highest when pregnant women are affected by both [18]. To date, it remains unknown whether malaria and undernutrition act additively or even synergistically to affect pregnancy outcome, or whether effect measure modification of the impact of malaria on birthweight by nutritional status is present [18].

Malaria and macronutrient undernutrition in pregnancy have each been associated with increased infant morbidity and mortality. Many of the 900,000 LBW deliveries attributed to malaria take place in areas where maternal nutrition is poor, but the extent to which undernutrition contributes to this burden is unknown [3]. In utero exposure to malaria or undernutrition may affect the immunocompetence of the offspring, and could thus alter the risk of malaria-related morbidity and mortality in infancy [5, 23, 24]. Gestational malaria and undernutrition have been associated with suboptimal postnatal growth, suggesting in utero insults have lasting effects on the growth trajectory [25]. Growth faltering in utero and early infancy results in short adult stature, itself a risk factor for LBW, highlighting the cyclical, transgenerational effects of poor nutrition (Fig. 1) [26]. Moreover, LBW due to maternal macronutrient deficiency has been epidemiologically linked to adulthood non-communicable diseases $[5,27,28]$.

\section{Effects of nutrition on antimalarial antibody}

In undernourished children, research indicates that antibody responses to various infections remain adequate, 
yet most such studies involve a small number of subjects and rarely assess antibody functionality [29]. By contrast, there is evidence to suggest that undernutrition reduces immunological response to vaccines [30] and diminishes antibody-mediated antimalarial immunity [31, 32].

Limited studies have assessed the effect of maternal macronutrient undernutrition on acquisition or maintenance of $P$. falciparum antibody responses. In pregnancy, the most important antibody target is PfVAR2CSA, a parasite protein inserted in the surface of infected erythrocytes that mediates placental parasite sequestration [33]. Susceptibility to malaria is greatest in first pregnancy, when women lack antibody to the PFVAR2CSA protein [33], and this antibody has been correlated with protection against placental malaria, LBW and anaemia [34].

In Papua New Guinea and Malawi, maternal MUAC was not associated with levels of antibody to PfVAR2CSAexpressing infected erythrocytes but maternal weight was inversely correlated with antibody levels to $P$. falciparum merozoite surface protein 2 and to PfVAR2CSA [35]. In a different study, Malawian women with a BMI of less than $18.5 \mathrm{~kg} / \mathrm{m}^{2}$ at first antenatal visit had higher antibody levels to PfVAR2CSA at 36 gestational weeks than those with a normal or raised BMI [36]. A similar relationship was found for low socio-economic status: the association between undernutrition and antibody levels may be a result of increased exposure to malaria due to poor housing and limited access to bed nets and antimalarials [36]. In the same cohort, lipid-based nutrient supplementation (LNS) during pregnancy did not improve anti-malarial antibody responses [36]. To untangle the overlapping exposures relating to malaria immunity and undernutrition, further randomised trials of interventions may be needed.

Even if antibody levels or functionality are not affected, maternal macronutrient undernutrition might affect the ability of phagocytic cells to clear infection [37]. Undernutrition and placental malaria appear to reduce transplacental transfer of protective antibodies to some pathogens, but not to others [38, 39]. Malaria in pregnancy and undernutrition may also affect vaccine response in the offspring $[29,40]$ - such potential intergenerational effects require urgent evaluation.

\section{Effects of malaria and nutrition on cellular immune responses}

Pregnancy is characterised by a switch from a proinflammatory T-helper 1 (Th1) to a Th2 cytokine response, which protects the fetal allograft from rejection by the maternal immune system [41]. Although inflammation plays critical roles in implantation, placentation and birth, at other time points, it may contribute to adverse pregnancy outcomes including LBW [41]. Placental malaria causes local inflammatory cytokine and chemokine production, which is associated with LBW, PTB and FGR [33], while macronutrient undernutrition has been associated with reduced $\mathrm{T}$-cell activation (due to lowered circulating glucose), a decrease in total T-cell numbers and an altered cytokine profile [42]. The impact of the dysregulated cellular immune response in undernourished women on fighting malarial infection remains poorly understood. Infections other than malaria are likely to play an important role too [43], in particular if resulting in systemic and/or placental inflammation, which have been associated with adverse pregnancy outcomes [44]. These infections may be more common and detrimental amongst undernourished women.

\section{Effects on fetal nutrient supply}

Placental malaria affects transplacental transport of nutrients, including amino acids and glucose [45]; this is most apparent when there is intervillositis (accumulation of malaria pigment-containing mononuclear cells) [33]. In undernourished women, compensatory upregulation of transplacental amino acid transport can occur in response to reduced amino acid availability [46], but this could be impaired by placental malaria, thereby limiting fetal nutrient supply even further.

\section{Effects on placental development}

A growing body of evidence suggests that malaria infection in early pregnancy increases the risk of adverse pregnancy outcomes independently of infections following organogenesis and placentation [47]. While the impact of pre-conceptional malaria is unknown, nutritional status at conception has important consequences for embryonic and placental development and fetal growth [48], and maternal weight and gestational weight gain both influence placental weight [49]. Further, both malaria and undernutrition are known to negatively affect trophoblast migration and invasion capacity [50, 51], important determinants of the development of maternal placental blood flow. In Congolese women, early pregnancy parasitaemia was associated with increased uterine artery resistance in undernourished but not in wellnourished women [20]. Malaria and undernutrition may both affect vascular development of the fetal placental circulation [52].

\section{Effects of malaria and undernutrition on growth-related hormones \\ Leptin}

The adipokine leptin increases Th1 cell numbers and cytokine secretion [42]. Low levels of leptin are seen in undernourished women [53] and are predictive of mortality in undernourished children [54]; they have also been reported in placental malaria [55]. Nevertheless, the consequences of suppressed maternal leptin for pregnancy outcome remain unknown. 


\section{Cortisol}

Both protein-energy undernutrition and malaria infection are associated with elevated serum cortisol levels $[56,57]$, which may translate into increased fetal cortisol exposure. Undernutrition can reduce the function of 11$\beta$ hydroxysteroid dehydrogenase, the gatekeeper for fetal cortisol exposure; effects of placental malaria on its activity remain unknown [22]. Increased fetal cortisol levels have been associated with reduced thymus size and impaired lymphopoiesis and with effects on the hypothalamus-pituitary-adrenal axis and on both cellular and humoral immunity [53].

\section{IGF axis}

The IGF axis is a principal driver of fetal growth [22]. Inflammatory cytokines, such as TNF $\alpha$ and IL-1 $\beta$, produced in response to malaria decrease placental amino acid uptake [45] and decrease IGF1 [22], as does undernutrition [58], suggesting malaria and undernutrition might act synergistically to affect fetal growth. In utero stress can cause neuroendocrine changes that predispose to diseases such as diabetes; altering the regulation of IGF levels may be one possible pathway [59].

\section{The conundrum of co-existing macro- and micronutrient deficiencies}

Pregnant women with macronutrient undernutrition are prone to concurrent micronutrient deficiencies, with iron deficiency probably being the most common. Attempts should be made to take these into account when studying malaria-nutrition relationships $[15,60]$. In children, iron deficiency may protect from severe malaria, and iron supplementation without antimalarial chemoprophylaxis exacerbates infection and mortality risk [61]. Iron deficiency may reduce the risk of placental malaria [62], yet it increases the risk of maternal anaemia and could cause LBW directly or via anaemia-dependent effects [63]. Iron supplementation combined with adequate malaria prevention appears not to increase the risk of maternal Plasmodium infection [63-65].

Furthermore, both malaria infection and macronutrient malnutrition, particularly protein deficiency, are causes of maternal anaemia, itself associated with LBW $[2,22]$. Other infectious causes of iron deficiency and anaemia, such as intestinal helminth infection, may also be important, given their potential modifying impact on malaria, nutrient absorption and LBW risk [66, 67]. Folate supplementation in pregnancy prevents neural tube defects, but may increase infection risk and, in high doses, could result in failure of antifolate antimalarials [68]. Multiple micronutrient supplements decrease LBW, FGR and stillbirths [69]; however, whether deficiencies of micronutrients such as zinc, calcium and vitamin A interact with malaria in pregnancy remains unclear [70].

Assessment of macronutrient nutritional status in pregnancy Assessment of maternal nutrition forms part of the WHO's focused antenatal care strategy [71], which states that women with a low booking BMI $\left(<18.5 \mathrm{~kg} / \mathrm{m}^{2}\right)$ should receive support. Many pregnant women still seek antenatal care late, and BMI tends to increase as a result of gestational weight gain [12]; therefore, women who might benefit from nutrition-malaria interventions could be missed. MUAC varies little over gestation, and can help to identify undernourished women who are at risk of delivering a LBW baby [72], but cut-points for low MUAC and BMI may not identify the same women [72]. Maternal height less than $155 \mathrm{~cm}$ (indicating childhood stunting) and low gestational weight gain are also associated with PTB and FGR [26]. These measures need to be evaluated in relation to malaria risk, although the best and most applicable nutrition-related predictor of adverse pregnancy outcome remains to be clarified.

\section{Current tools to combat malaria and macronutrient undernutrition in pregnancy}

To protect pregnant women from malaria, the WHO currently recommends the use of insecticide-treated bed nets, monthly intermittent preventive treatment with sulphadoxine-pyrimethamine from second trimester onwards, and malaria case detection and management [73]. By contrast, current management of macronutrient undernutrition is largely limited to dietary advice and improving women's economic status, although studies demonstrate that balanced energy-protein supplements are beneficial [74, 75]. Nevertheless, given the omnipresence of poverty, dietary advice may have limited effect in LMICs [76].

Balanced energy-protein supplementation was shown to improve pregnancy outcomes and increase birthweight by an average of $100 \mathrm{~g}$ in undernourished women [77]. In The Gambia, daily dietary supplementation with high-energy groundnut biscuits $(4.3 \mathrm{MJ} /$ day) improved gestational weight gain and increased birthweight; effects were greatest in primigravidae and in the hunger (malaria) season [14]. Lipid-based nutrient supplements (LNS) may be alternative strategies to improve birthweight and gestational length. In Burkina Faso, daily LNS (1.56 MJ/372 kcal, $14.7 \mathrm{~g}$ protein and micronutrients) increased gestational length amongst women with a low baseline BMI and anaemia and had greatest impact during the rainy season [78]. In Ghana and Malawi, daily LNS (118 kcal, including 20 micronutrients) increased length $(\sim 4-5 \mathrm{~mm})$ and weight $(\sim 50 \mathrm{~g})$ at birth, and had greatest effects on birth size amongst primigravid, anaemic and short-statured women (Ghana) [79]. In 
Malawi, LNS was most beneficial in women who had HIV infection or malaria [80]. Multiple micronutrient and iron/folic acid supplements may also significantly increase birthweight and reduce LBW and stillbirth, but effect sizes tend to be modest [77]. Taken together these results suggest that nutritional supplementation may be most beneficial in vulnerable women, such as primigravidae and women living with HIV, who have no or impaired immunity to pregnancy-associated malaria and are at high risk of undernutrition, malaria and LBW [22]. Adolescent women are another potential target group, being at increased risk of undernutrition, malaria and adverse pregnancy outcomes [81].
Other approaches to improve maternal nutritional status whilst reducing malaria risk could be of use. Intermittent preventive treatment with sulphadoxinepyrimethamine and azithromycin reduced the risk of LBW, improved birthweight and gestational length, and prevented growth faltering in early infancy in two of three clinical trials [82, 83]. In Papua New Guinea and Malawi, it was associated with increased gestational weight gain (Ashorn P, unpublished observations) [12]. Beyond azithromycin's antimalarial effects, underlying mechanisms could involve reduction in maternal energy expenditure following clearance of infections, increased appetite once infection resolves, increased nutrient

Table 1 Key research gaps in the study of nutritional status and malaria in pregnancy

\begin{tabular}{|c|c|}
\hline & Research area \\
\hline Burden & $\begin{array}{l}\text { Evaluate the extent to which undernutrition and malaria in pregnancy co-exist } \\
\text { - DHSS data, pooled analysis of relevant pregnancy cohort studies }\end{array}$ \\
\hline Risk of malaria & $\begin{array}{l}\text { Determine the relationship between maternal nutritional status and risk of malaria parasitaemia } \\
\text { - Longitudinal cohort studies with frequent molecular infection monitoring }\end{array}$ \\
\hline Effect modification & $\begin{array}{l}\text { Determine whether malaria and nutritional status interact to worsen pregnancy outcomes (LBW, SGA, PTB, stillbirth) } \\
\text { - Pooled analysis of pregnancy cohort studies, new longitudinal studies measuring most known confounders }\end{array}$ \\
\hline Conception and early pregnancy & $\begin{array}{l}\text { Examine effects of undernutrition and malaria at conception and in early pregnancy on outcomes } \\
\text { - Longitudinal observational or interventional studies beginning before conception or in first trimester including } \\
\text { repeated measures of malaria and nutritional status } \\
\text { - Effect of early pregnancy malaria and undernutrition on rates of miscarriage, stillbirth, LBW }\end{array}$ \\
\hline $\begin{array}{l}\text { Concomitant micronutrient } \\
\text { deficiencies }\end{array}$ & $\begin{array}{l}\text { Investigate possible interactions between deficiencies of micronutrients such as iron and gestational malaria } \\
\text { - Pregnancy cohort studies that evaluate malaria indices, micronutrient status, and pregnancy outcomes }\end{array}$ \\
\hline \multirow[t]{2}{*}{ Infant effects } & Study the effects of maternal undernutrition and malaria on infant morbidity, mortality, growth and infection risk \\
\hline & $\begin{array}{l}\text { Evaluate the consequences of maternal undernutrition and malaria for development of the infant's immune } \\
\text { system } \\
\text { Investigate whether children born with LBW due to undernutrition and/or malaria would benefit from increased } \\
\text { nutritional support and malaria prevention in infancy } \\
\text { - Longitudinal cohort studies with well-supported follow-up mechanisms } \\
\text { - Randomised trials of packaged malaria and nutrition interventions for at-risk infants }\end{array}$ \\
\hline
\end{tabular}

Anthropometrics, cytokines and Relate anthropometric measurements in pregnancy to biochemical markers of nutritional status (albumin), hormones regulators of the nutrition/immunity interface (e.g. leptin), and adverse pregnancy outcomes in malaria-endemic areas

- Determine the interplay between undernutrition, Th1/Th2 balance, placental malaria-associated inflammation, and LBW

Gut function

Examine effects of environmental enteric dysfunction, and of changes in gut microbiome, on maternal nutrition and malaria susceptibility Evaluate the impact of macronutrient status on efficacy of antimalarials (including IPTp) in pregnant women.

Gestational weight gain

Evaluate strategies to improve gestational weight gain in undernourished women to counteract the effect of placental malaria

- Combining nutrient or energy supplementation with antimalarial interventions

Investigate novel mechanisms by which IPTp may work to improve maternal weight gain

- Microbiome studies, pre and post IPTp, and using different IPTp candidates

- Intestinal helminth - nutrition - malaria interactions

Antenatal care

Design and test approaches that integrate malaria-nutrition interventions

- Combined or factorial trials of nutritional supplementation and malaria detection and prevention

- Identify target groups for enhanced nutritional support and malaria protection, e.g. undernourished women, primigravidae, and adolescents.

Immunity

Examine the relationship between nutritional status and antibody-mediated immunity to PM, controlling for differences in malaria exposure among participants

Evaluate the effect of nutritional intervention on antibody-mediated immunity to PM

Placental studies Investigate potential overlapping effects of malaria and macronutrient undernutrition on placental nutrient transport 
availability to the fetus, and effects on maternal gut microbiota that improve dietary energy harvest [84]. Infection and nutrition-related inflammatory processes have been associated with adverse pregnancy outcomes, including PTB [44]. Azithromycin has anti-inflammatory activity and may clear other infections responsible for inflammatory responses [83].

\section{Building the evidence base}

Many pregnant women are at risk of both undernutrition and malaria, yet few studies have investigated gestational malaria-nutrition interactions. Given their potential consequences for fetal growth and development, an expanded evidence base on malaria-nutrition interactions in pregnancy is urgently needed, with closer collaboration between malariologists, nutritionists and reproductive health specialists. Table 1 summarises current research gaps.

Better mapping the overlapping burdens of undernutrition and malaria infection in pregnancy could be complemented by pooled analysis of data from pregnancy cohort studies that measured both nutritional and malariometric indices to confirm effect measure modification of the malaria-birthweight relationship by nutritional status. Studies are needed in early pregnancy and periconceptionally [48], when impacts on fetal development and immunological programming may be most profound. Determining the long-term effects of malaria and undernutrition, and research that aims to untangle the effects of mixed macroand micronutrient deficiencies for malaria immunity and placental malaria-associated adverse pregnancy outcomes, are needed. Similarly, the impact of poor nutrition in pregnancy on efficacy of malaria treatment and vaccines should be assessed.

\section{Potential new interventions}

There is mounting evidence that antenatal identification and tailored management of high-risk mothers may prevent adverse pregnancy outcomes due to malaria and undernutrition, and further research, such as pooled analysis, may provide additional evidence for this approach. Potential target groups include adolescent, primigravid, undernourished, HIV-infected or anaemic women. These women in particular may benefit from enhanced malaria prevention strategies combined with effective nutritional supplementation, which can be delivered conjointly through antenatal care systems. Drugs that improve gestational weight gain in undernourished women, or that clear other deleterious infections (e.g. Chlamydia trachomatis) whilst providing antimalarial protection, also deserve further evaluation [12, 83].

\section{Conclusions}

Macronutrient undernutrition, alone and in concert with placental malaria, can deleteriously impact fetal growth, and could affect both immunocompetence (and infection risk and mortality in the offspring), and long-term health. To meet the World Health Assembly's targets for improving nutrition status, including decreases in maternal anaemia and LBW, improvement of malaria prevention will also be necessary given the major contributions of malaria to both LBW and anaemia.

Joint efforts by nutritionists and malaria experts are needed to determine the burden and significance of malaria-nutrition interactions in pregnancy, and to develop interventions that protect pregnant women and their children from this dangerous dyad.

\section{Abbreviations}

BMI: body mass index; FGR: fetal growth restriction; LBW: low birthweight; LMICs: low-and-middle-income countries; LNS: lipid-based nutrient supplements; MUAC: mid-upper arm circumference; PTB: preterm birth; Th: T helper cell; WHO: World Health Organization

\section{Acknowledgements}

We thank Bernard Brabin and R Matthew Chico for comments on the manuscript, and Albert Serra-Pou for assistance in preparing Fig. 1. JEC received funding from the National Institute of Allergy and Infectious Diseases at the National Institutes of Health Training in Infectious Disease Epidemiology' training grant \#5-T32-Al070114. SJR is supported by a Program Grant from the National Health and Medical Research Council of Australia. The funders had no role in the design, writing, or decision to publish this study

Authors' contributions

HWU and SJR wrote the first draft, SJR developed the concept, and PA, JEC and KGD commented on subsequent drafts of the article. All authors read and approved the final version of the manuscript.

\section{Competing interests}

The authors declare that have no competing interests.

\section{Author details}

'Department of Medicine at the Doherty Institute, The University of Melbourne, Melbourne, Victoria, Australia. ${ }^{2}$ Simpson Centre for Reproductive Health, Edinburgh Royal Infirmary, Edinburgh, UK. ${ }^{3}$ Department of Paediatrics, University of Tampere School of Medicine, Tampere, Finland. ${ }^{4}$ Department for International Health, University of Tampere School of Medicine, Tampere, Finland. ${ }^{5}$ Department of Paediatrics, Tampere University Hospital, Tampere, Finland. ${ }^{6}$ Department of Epidemiology, University of North Carolina-Chapel Hill, Chapel Hill, NC, USA. PProgram in International and Community Nutrition and Department of Nutrition, University of California, Davis, CA, USA.

Received: 11 June 2016 Accepted: 15 September 2016

Published online: 19 September 2016

\section{References}

1. Christian P, Mullany LC, Hurley KM, Katz J, Black RE. Nutrition and maternal, neonatal, and child health. Semin Perinatol. 2015;39(5):361-72.

2. Black RE, Victora CG, Walker SP, Bhutta ZA, Christian P, de Onis M, Ezzati M, Grantham-McGregor S, Katz J, Martorell R, et al. Maternal and child undernutrition and overweight in low-income and middle-income countries. Lancet. 2013;382(9890):427-51.

3. Walker PG, Ter Kuile FO, Garske T, Menendez C, Ghani AC. Estimated risk of placental infection and low birthweight attributable to Plasmodium falciparum malaria in Africa in 2010: a modelling study. Lancet Glob Health. 2014;2(8):e460-7.

4. Desai M, ter Kuile FO, Nosten F, McGready R, Asamoa K, Brabin B, Newman $\mathrm{RD}$. Epidemiology and burden of malaria in pregnancy. Lancet Infect Dis. 2007;7(2):93-104.

5. Hanson MA, Gluckman PD. Early developmental conditioning of later health and disease: physiology or pathophysiology? Physiol Rev. 2014;94(4):1027-76. 
6. World Health Organization. Global Strategy for Women's, Children's and Adolescents' Health 2016-2030. Geneva: WHO; 2015.

7. Sustainable Development Goals. http://www.un.org/sustainabledevelopment/ sustainable-development-goals/. Accessed 16 Sept 2016.

8. Dellicour S, Tatem AJ, Guerra CA, Snow RW, ter Kuile FO. Quantifying the number of pregnancies at risk of malaria in 2007: a demographic study. PLoS Med. 2010;7(1):e1000221.

9. Katona P, Katona-Apte J. The interaction between nutrition and infection. Clin Infect Dis. 2008;46(10):1582-8.

10. Raiten DJ, Sakr Ashour FA, Ross AC, Meydani SN, Dawson HD, Stephensen CB, Brabin BJ, Suchdev PS, van Ommen B. Inflammation and Nutritional Science for Programs/Policies and Interpretation of Research Evidence (INSPIRE). J Nutr. 2015;145(5):1039S-108S.

11. Maternal anthropometry and pregnancy outcomes. A WHO Collaborative Study. Bull World Health Organ. 1995;73 Suppl:1-98.

12. Unger HW, Wangnapi RA, Ome-Kaius M, Boeuf P, Karl S, Mueller I, Rogerson SJ. Azithromycin-containing intermittent preventive treatment in pregnancy affects gestational weight gain, an important predictor of birthweight in Papua New Guinea - an exploratory analysis. Matern Child Nutr. 2015. Ahead of print.

13. Rayco-Solon P, Fulford AJ, Prentice AM. Differential effects of seasonality on preterm birth and intrauterine growth restriction in rural Africans. Am J Clin Nutr. 2005;81(1):134-9.

14. Ceesay SM, Prentice AM, Cole TJ, Foord F, Weaver LT, Poskitt EM, Whitehead RG. Effects on birth weight and perinatal mortality of maternal dietary supplements in rural Gambia: 5 year randomised controlled trial. BMJ. 1997; 315(7111):786-90.

15. Shankar AH. Nutritional modulation of malaria morbidity and mortality. J Infect Dis. 2000;182 Suppl 1:S37-53.

16. Ferreira E, Alexandre MA, Salinas JL, de Siqueira AM, Benzecry SG, de Lacerda MV, Monteiro WM. Association between anthropometry-based nutritional status and malaria: a systematic review of observational studies. Malar J. 2015;14(1):346

17. Nyakeriga AM, Troye-Blomberg M, Chemtai AK, Marsh K, Williams TN. Malaria and nutritional status in children living on the coast of Kenya. Am J Clin Nutr. 2004;80(6):1604-10.

18. Landis SH, Lokomba V, Ananth CV, Atibu J, Ryder RW, Hartmann KE, Thorp JM, Tshefu A, Meshnick SR. Impact of maternal malaria and under-nutrition on intrauterine growth restriction: a prospective ultrasound study in Democratic Republic of Congo. Epidemiol Infect. 2009;137(2):294-304.

19. Lovel HJ, Newby RM, Hillier VF. Severe placental malaria and maternal shortness, thinness, and small skeletal size in rural Congo: cohort study. BMJ. 2005;331(7530):1439-40.

20. Griffin JB, Lokomba V, Landis SH, Thorp Jr JM, Herring AH, Tshefu AK, Rogerson SJ, Meshnick SR. Plasmodium falciparum parasitaemia in the first half of pregnancy, uterine and umbilical artery blood flow, and foetal growth: a longitudinal Doppler ultrasound study. Malar J. 2012;11(1):319.

21. McClure EM, Meshnick SR, Lazebnik N, Mungai P, King CL, Hudgens M, Goldenberg RL, Siega-Riz AM, Dent AE. A cohort study of Plasmodium falciparum malaria in pregnancy and associations with uteroplacental blood flow and fetal anthropometrics in Kenya. Int J Gynaecol Obstet. 2014;126(1):78-82.

22. Umbers AJ, Aitken EH, Rogerson SJ. Malaria in pregnancy: small babies, big problem. Trends Parasitol. 2011;27(4):168-75.

23. Moore SE, Fulford AJ, Wagatsuma Y, Persson LA, Arifeen SE, Prentice AM. Thymus development and infant and child mortality in rural Bangladesh. Int J Epidemiol. 2014:43(1):216-23.

24. Borgella S, Fievet N, Huynh BT, Ibitokou S, Hounguevou G, Affedjou J, Sagbo JC, Houngbegnon P, Guezo-Mevo B, Massougbodji A, et al. Impact of pregnancy-associated malaria on infant malaria infection in southern Benin. PLoS One. 2013;8(11):e80624.

25. Walther B, Miles DJ, Crozier S, Waight P, Palmero MS, Ojuola O, Touray E, van der Sande $M$, Whittle $H$, Rowland-Jones $S$, et al. Placental malaria is associated with reduced early life weight development of affected children independent of low birth weight. Malar J. 2010;9:16.

26. Kozuki N, Katz J, Lee AC, Vogel JP, Silveira MF, Sania A, Stevens GA, Cousens $S$, Caulfield LE, Christian $P$, et al. Short maternal stature increases the risk of small-for-gestational-age and preterm births in low- and middle-income countries: individual participant data meta-analysis and population attributable fraction. J Nutr. 2015;145(11):2542-50.

27. Luxemburger C, McGready R, Kham A, Morison L, Cho T, Chongsuphajaisiddhi T, White NJ, Nosten F. Effects of malaria during pregnancy on infant mortality in an area of low malaria transmission. Am J Epidemiol. 2001;154(5):459-65.

28. Moore SE. Early life nutritional programming of health and disease in The Gambia. J Dev Orig Health Dis. 2016;7(2):123-31.

29. Rytter MJ, Kolte L, Briend A, Friis H, Christensen VB. The immune system in children with malnutrition-a systematic review. PLoS One. 2014;9(8):e105017.

30. Fabrizi F, Dixit V, Martin P, Jadoul M, Messa P. Meta-analysis: the impact of nutritional status on the immune response to hepatitis $B$ virus vaccine in chronic kidney disease. Dig Dis Sci. 2012;57(5):1366-72.

31. Fillol F, Cournil A, Boulanger D, Cisse B, Sokhna C, Targett G, Trape JF, Simondon F, Greenwood B, Simondon KB. Influence of wasting and stunting at the onset of the rainy season on subsequent malaria morbidity among rural preschool children in Senegal. Am J Trop Med Hyg. 2009;80(2):202-8.

32. Fillol F, Sarr JB, Boulanger D, Cisse B, Sokhna C, Riveau G, Simondon KB, Remoue F. Impact of child malnutrition on the specific anti-Plasmodium falciparum antibody response. Malar J. 2009:8:116.

33. Rogerson SJ, Hviid L, Duffy PE, Leke RF, Taylor DW. Malaria in pregnancy: pathogenesis and immunity. Lancet Infect Dis. 2007;7(2):105-17.

34. Duffy PE, Fried M. Antibodies that inhibit Plasmodium falciparum adhesion to chondroitin sulfate $\mathrm{A}$ are associated with increased birth weight and the gestational age of newborns. Infect Immun. 2003;71(11):6620-3.

35. Teo A, Hasang W, Randall LM, Feng G, Bell L, Unger H, Langer C, Beeson JG, Siba PM, Mueller I, et al. Decreasing malaria prevalence and its potential consequences for immunity in pregnant women. J Infect Dis. 2014;210(9): 1444-55.

36. Chandrasiri UP, Fowkes FJ, Richards JS, Langer C, Fan YM, Taylor SM, Beeson JG, Dewey KG, Maleta K, Ashorn P, et al. The impact of lipid-based nutrient supplementation on anti-malarial antibodies in pregnant women in a randomized controlled trial. Malar J. 2015;14:193.

37. Munson D, Franco D, Arbeter A, Velez H, Vitale JJ. Serum levels of immunoglobulins, cell-mediated immunity, and phagocytosis in proteincalorie malnutrition. Am J Clin Nutr. 1974;27(6):625-8.

38. Cumberland P, Shulman CE, Maple PA, Bulmer JN, Dorman EK, Kawuondo K, Marsh K, Cutts FT. Maternal HIV infection and placental malaria reduce transplacental antibody transfer and tetanus antibody levels in newborns in Kenya. J Infect Dis. 2007;196(4):550-7.

39. Atwell JE, Thumar B, Robinson LJ, Tobby R, Yambo P, Ome-Kaius M, Siba PM, Unger HW, Rogerson SJ, King CL, et al. Impact of placental malaria and hypergammaglobulinemia on transplacental transfer of respiratory syncytial virus antibody in Papua New Guinea. J Infect Dis. 2015;213(3):423-31.

40. Malhotra I, McKibben M, Mungai P, McKibben E, Wang X, Sutherland LJ, Muchiri EM, King CH, King CL, LaBeaud AD. Effect of antenatal parasitic infections on anti-vaccine lgG levels in children: a prospective birth cohort study in Kenya. PLoS Negl Trop Dis. 2015;9(1):e0003466.

41. Raghupathy R. Th1-type immunity is incompatible with successful pregnancy. Immunol Today. 1997;18(10):478-82.

42. Gerriets VA, Maclver NJ. Role of T cells in malnutrition and obesity. Front Immunol. 2014;5:379.

43. Chico RM, Mayaud P, Ariti C, Mabey D, Ronsmans C, Chandramohan D. Prevalence of malaria and sexually transmitted and reproductive tract infections in pregnancy in sub-Saharan Africa: a systematic review. JAMA. 2012;307(19):2079-86.

44. Romero R, Dey SK, Fisher SJ. Preterm labor: one syndrome, many causes. Science. 2014;345(6198):760-5.

45. Boeuf P, Aitken EH, Chandrasiri U, Chua CL, Mclnerney B, McQuade L, Duffy M, Molyneux M, Brown G, Glazier J, et al. Plasmodium falciparum malaria elicits inflammatory responses that dysregulate placental amino acid transport. PLoS Pathog. 2013;9(2):e1003153.

46. Gaccioli $F$, Lager $S$, Powell $T L$, Jansson T. Placental transport in response to altered maternal nutrition. J Dev Orig Health Dis. 2013;4(2):101-15.

47. Huynh BT, Cottrell G, Cot M, Briand V. Burden of malaria in early pregnancy: a neglected problem? Clin Infect Dis. 2014;60(4):598-604.

48. Hambidge KM, Krebs NF, Westcott JE, Garces A, Goudar SS, Kodkany BS, Pasha O, Tshefu A, Bose CL, Figueroa L, et al. Preconception maternal nutrition: a multi-site randomized controlled trial. BMC Pregnancy Childbirth. 2014;14:111

49. Gernand AD, Christian P, Paul RR, Shaikh S, Labrique AB, Schulze KJ, Shamim AA, West Jr KP. Maternal weight and body composition during pregnancy are associated with placental and birth weight in rural Bangladesh. J Nutr. 2012;142(11):2010-6. 
50. Umbers AJ, Stanisic DI, Ome M, Wangnapi R, Hanieh S, Unger HW, Robinson $\sqcup$, Lufele E, Baiwog F, Siba PM, et al. Does malaria affect placental development? Evidence from in vitro models. PLoS One. 2013;8(1):e55269.

51. Schulz LC, Widmaier EP. The effect of leptin on mouse trophoblast cell invasion. Biol Reprod. 2004;71(6):1963-7.

52. Conroy AL, Silver KL, Zhong K, Rennie M, Ward P, Sarma JV, Molyneux ME, Sled J, Fletcher JF, Rogerson S, et al. Complement activation and the resulting placental vascular insufficiency drives fetal growth restriction associated with placental malaria. Cell Host Microbe. 2013;13(2):215-26.

53. Palmer AC. Nutritionally mediated programming of the developing immune system. Adv Nutr. 2011;2(5):377-95.

54. Bartz S, Mody A, Hornik C, Bain J, Muehlbauer M, Kiyimba T, Kiboneka E, Stevens R, Bartlett J, St Peter JV, et al. Severe acute malnutrition in childhood: hormonal and metabolic status at presentation, response to treatment, and predictors of mortality. J Clin Endocrinol Metab. 2014; 99(6):2128-37

55. Conroy AL, Liles WC, Molyneux ME, Rogerson SJ, Kain KC. Performance characteristics of combinations of host biomarkers to identify women with occult placental malaria: a case-control study from Malawi. PLoS One. 2012; 6(12):e28540.

56. Soliman AT, ElZalabany MM, Salama M, Ansari BM. Serum leptin concentrations during severe protein-energy malnutrition: correlation with growth parameters and endocrine function. Metabolism. 2000;49(7):819-25.

57. Bouyou-Akotet MK, Issifou S, Meye JF, Kombila M, Ngou-Milama E, Luty AJ, Kremsner PG, Mavoungou E. Depressed natural killer cell cytotoxicity against Plasmodium falciparum-infected erythrocytes during first pregnancies. Clin Infect Dis. 2004:38(3):342-7.

58. Belkacemi L, Nelson DM, Desai M, Ross MG. Maternal undernutrition influences placental-fetal development. Biol Reprod. 2010;83(3):325-31.

59. Phillips DI, Matthews SG. Is perinatal neuroendocrine programming involved in the developmental origins of metabolic disorders? World J Diabetes. 2011:2(12):211-6.

60. Brabin L, Brabin BJ, Gies S. Influence of iron status on risk of maternal or neonatal infection and on neonatal mortality with an emphasis on developing countries. Nutr Rev. 2013;71(8):528-40.

61. Sazawal S, Black RE, Ramsan M, Chwaya HM, Stoltzfus RJ, Dutta A, Dhingra U, Kabole I, Deb S, Othman MK, et al. Effects of routine prophylactic supplementation with iron and folic acid on admission to hospital and mortality in preschool children in a high malaria transmission setting: community-based, randomised, placebo-controlled trial. Lancet. 2006; 367(9505):133-43.

62. Senga EL, Harper G, Koshy G, Kazembe PN, Brabin BJ. Reduced risk for placental malaria in iron deficient women. Malar J. 2011;10:47.

63. Pena-Rosas JP, De-Regil LM, Garcia-Casal MN, Dowswell T. Daily oral iron supplementation during pregnancy. Cochrane Database Syst Rev. 2015;7:CD004736.

64. Etheredge AJ, Premij Z, Gunaratna NS, Abioye Al, Aboud S, Duggan C, Mongi R, Meloney L, Spiegelman D, Roberts D, et al. Iron supplementation in iron-replete and nonanemic pregnant women in Tanzania: a randomized clinical trial. JAMA Pediatr. 2015;169(10):947-55.

65. Mwangi MN, Roth JM, Smit MR, Trijsburg L, Mwangi AM, Demir AY, Wielders $J P$, Mens PF, Verweij JJ, Cox SE, et al. Effect of daily antenatal iron supplementation on Plasmodium infection in Kenyan women: a randomized clinical trial. JAMA. 2015;314(10):1009-20.

66. Boel M, Carrara VI, Rijken M, Proux S, Nacher M, Pimanpanarak M, Paw MK, Moo O, Gay H, Bailey W, et al. Complex interactions between soiltransmitted helminths and malaria in pregnant women on the Thai-Burmese border. PLoS Negl Trop Dis. 2010;4(11):e887.

67. Hall A, Zhang Y, Macarthur C, Baker S. The role of nutrition in integrated programs to control neglected tropical diseases. BMC Med. 2012;10:41.

68. van Eijk AM, Ouma PO, Williamson J, Ter Kuile FO, Parise M, Otieno K, Hamel MJ, Ayisi JG, Kariuki S, Kager PA, et al. Plasma folate level and high-dose folate supplementation predict sulfadoxine-pyrimethamine treatment failure in pregnant women in Western Kenya who have uncomplicated malaria. J Infect Dis. 2008;198(10):1550-53.

69. Haider BA, Bhutta ZA. Multiple-micronutrient supplementation for women during pregnancy. Cochrane Database Syst Rev. 2015;11:CD004905.

70. Cox SE, Staalsoe T, Arthur P, Bulmer JN, Tagbor H, Hviid L, Frost C, Riley EM, Kirkwood BR. Maternal vitamin A supplementation and immunity to malaria in pregnancy in Ghanaian primigravids. Trop Med Int Health. 2005;10(12): 1286-97.
71. World Health Organization. WHO Antenatal Care Randomized Trial: Manual for the Implementation of the New Model. Geneva: WHO; 2002.

72. Ververs MT, Antierens A, Sackl A, Staderini N, Captier V. Which anthropometric indicators identify a pregnant woman as acutely malnourished and predict adverse birth outcomes in the humanitarian context? PLoS Curr. 2013;5. doi:10.1371/currents.dis.54a8b618c1bc031ea140 e3f2934599c8.

73. World Health Organization. WHO policy brief for the implementation of intermittent preventive treatment in malaria in pregnancy using sulfadoxine-pyrimethamine (IPTp-SP). Geneva: WHO; 2014.

74. Bhutta ZA, Das JK, Rizvi A, Gaffey MF, Walker N, Horton S, Webb P, Lartey A, Black RE. Evidence-based interventions for improvement of maternal and child nutrition: what can be done and at what cost? Lancet. 2013;382(9890): 452-77.

75. Dewey KG. Reducing stunting by improving maternal, infant and young child nutrition in regions such as South Asia: evidence, challenges and opportunities. Matern Child Nutr. 2016;12 Suppl 1:27-38.

76. Girard AW, Olude O. Nutrition education and counselling provided during pregnancy: effects on maternal, neonatal and child health outcomes. Paediatr Perinat Epidemiol. 2012;26 Suppl 1:191-204.

77. Imdad A, Bhutta ZA. Maternal nutrition and birth outcomes: effect of balanced protein-energy supplementation. Paediatr Perinat Epidemiol. 2012; 26 Suppl 1:178-90.

78. Toe LC, Bouckaert KP, De Beuf K, Roberfroid D, Meda N, Thas O, Van Camp J, Kolsteren PW, Huybregts LF. Seasonality modifies the effect of a lipidbased nutrient supplement for pregnant rural women on birth length. J Nutr. 2015;145(3):634-9.

79. Adu-Afarwuah S, Lartey A, Okronipa H, Ashorn P, Zeilani M, Peerson JM, Arimond M, Vosti S, Dewey KG. Lipid-based nutrient supplement increases the birth size of infants of primiparous women in Ghana. Am J Clin Nutr. 2015;101(4):835-46.

80. Ashorn P, Alho L, Ashorn U, Cheung YB, Dewey KG, Harjunmaa U, Lartey A, Nkhoma M, Phiri N, Phuka J, et al. The impact of lipid-based nutrient supplement provision to pregnant women on newborn size in rural Malawi: a randomized controlled trial. Am J Clin Nutr. 2015;101(2):387-97.

81. Althabe F, Moore JL, Gibbons L, Berrueta M, Goudar SS, Chomba E, Derman RJ, Patel A, Saleem S, Pasha O, et al. Adverse maternal and perinatal outcomes in adolescent pregnancies: The Global Network's Maternal Newborn Health Registry study. Reprod Health. 2015;12 Suppl 2:S8.

82. Luntamo M, Kulmala T, Mbewe B, Cheung YB, Maleta K, Ashorn P. Effect of repeated treatment of pregnant women with sulfadoxine-pyrimethamine and azithromycin on preterm delivery in Malawi: a randomized controlled trial. Am J Trop Med Hyg. 2010;83(6):1212-20.

83. Unger HW, Ome-Kaius M, Wangnapi RA, Umbers AJ, Hanieh S, Suen CS, Robinson L, Rosanas-Urgell A, Wapling J, Lufele E, et al. Sulphadoxinepyrimethamine plus azithromycin for the prevention of low birthweight in Papua New Guinea: a randomised controlled trial. BMC Med. 2015;13:9.

84. Angelakis $\mathrm{E}$, Merhej $\mathrm{V}$, Raoult D. Related actions of probiotics and antibiotics on gut microbiota and weight modification. Lancet Infect Dis. 2013;13(10): 889-99.

\section{Submit your next manuscript to BioMed Central and we will help you at every step:}

- We accept pre-submission inquiries

- Our selector tool helps you to find the most relevant journal

- We provide round the clock customer support

- Convenient online submission

- Thorough peer review

- Inclusion in PubMed and all major indexing services

- Maximum visibility for your research

Submit your manuscript at www.biomedcentral.com/submit 